\section{Tourism and Health, Risks, and Challenges}

Ann Hindley and Maeve Marmion

Faculty of Business and Management, University of Chester, Chester, UK

\section{Synonyms}

Communicable diseases; Risk taking; Sex tourism; Travel health

\section{Definition}

While the entry "tourism, health, and well-being" articulates the consensus that tourism experiences can have health benefits for individuals and societies, there are also health risks involved when it comes to international travel. Tourists and tourism organizations need to be aware of and to manage such risks in order to mitigate the potentially farreaching health consequences. By its nature, tourism involves the movement of people from place to place and as such increases the unplanned exposure of tourism stakeholders to a variety of health-related risks. This entry takes a tourism, tourist, and community perspective rather than a health or medical practitioner stance, in order to highlight some of the risks and challenges that may emerge in the context of tourism and health.

\section{An Introduction to the Health Risks of Tourism}

Communicable diseases, behavioral changes, differences in hygiene and sanitation processes, and other social, personal, and external factors are all worth serious consideration when understanding how health and tourism are related. Furthermore, the tourism industry can be a façade for some darker aspects of social interaction, e.g., in facilitating the supply and demand of sex, drugs, and other experiences that can have serious impacts on the health and well-being of the most vulnerable members of host communities.

The various health risks of tourism can affect a whole range of different stakeholders including the communities that host tourists within their hotels, restaurants, public spaces, and even in their own private homes. International tourists in particular cross borders and enter destinations through airports and seaports and spend time in a variety of different places. Such destinations might be well established in terms of its tourism infrastructure and its resources and others less well equipped with the necessary tools to mitigate any associated health risks. Furthermore, the nature of the destination may be relevant, whereby highly developed economies or places may have very different risk factors for tourists and communities to those in lesser developed countries. Equally natural environments may have different risk factors to urban or man-made environments, 
and these can be important factors in planning and managing tourism and tourism-related health risks.

This entry will discuss international tourism from two main perspectives: firstly in relation to the spread of disease in the context of travel and travel health and secondly in relation to the increased risk-taking behavior of tourists and the nature of some of the activities they may seek to partake in. By doing so, this allows for an exploration of some of the key health challenges that arise in the context of tourism from a variety of stakeholder perspectives in order to make the case for individual and industry responsibility for the well-being and health of our tourists and for our global tourism communities.

\section{Tourism and the Spread of Disease and Infection}

Tourism is forecast to grow to 1.8 billion travelers by 2030 (World Tourism Organization (UNWTO) 2017), and international travel is a factor that can "foster and increase the spread of communicable diseases" (World Health Organization 2018a). Such diseases include those passed directly from infected person-to-person or those indirectly transmitted via "an animal, vector or the inanimate environment" (Thombley and Stier 2010, p. 8). Tourists are ultimately going to experience different environmental factors than the ones they are familiar with as part of their travels and as they interact with new people and experience different ways of life. Furthermore, there are a variety of different risks around the quality of air they breathe, the types of food they eat, the water they use, native species they may encounter, and a whole host of other new sources of potential risk. As such, tourists often get caught out and become unwell while abroad and also may play a role in the transmission of diseases in the process.

\section{Borders and Transportation}

Modes of transportation within tourism can present challenges with regard to health. For instance, transport facilitates the movement of individuals and groups of tourists via air, sea, and land, and each of these creates opportunities for the transmission of disease and infection. There are a whole host of airborne diseases that travelers may be at risk of contracting. For example, international travelers are important when understanding the global spread of influenza (LaRoque and Ryan 2015). The close proximity of other travelers and the spread of influenza are a concern for large tour groups such as pilgrims visiting the Hajj and spending an extended period of time together (LaRoque and Ryan 2015). Influenza or "flu" can also break out on or be transported by aircraft, which is more likely to be caused by a high number of passengers spending time in very close quarters with others who are infected and sneeze, cough, and/or touch shared surfaces while on board, as opposed to the general perception that the ventilation systems might be to blame (World Health Organisation 2012). In-flight transmission has been specifically documented in the case of severe acute respiratory syndrome (SARS) in 2003, with the disease spreading within weeks from China to Hong Kong, Vietnam, Singapore, and Canada (LaRoque and Ryan 2015). Furthermore, reduced flying times and longer distance flights allow for the mass transportation of tourists and travelers across international borders and indeed intercontinental regions, and hence this greatly increases the challenge of managing borders and entry points from a global health perspective.

Another concern when trying to prevent disease spreading across borders is that of meningococcal disease. Saudi Arabia is one example, whereby as a preventative action, they impose a meningococcal vaccination as a prerequisite for visitor entry (World Health Organisation 2012). This illustrates that while on the surface travel health can be an individual and/or delimited concern, it can actually have serious if not fatal consequences if borders and entry ports are not managed with health as a key consideration. For instance, meningococcal disease is a potentially fatal medical emergency which, given that it is spread through respiratory or throat secretions (World Health Organisation 2012), can be passed from traveler to traveler or from tourist to local residents through their seemingly harmless day- 
to-day interactions during transit and within destinations.

In addition to air travel and border controls, the closed conditions in shipping can also create challenges in the management of travel health (Laganà et al. 2017). For example, the Legionella species, an aerobic disease that includes Pontiac fever and Legionnaires' disease and which can result in a fatal form of pneumonia (Erdogan and Arslan 2015), can potentially spread through the air conditioning or water pipes on cruise ships and ferries (Laganà et al. 2017). While structural maintenance of the ship can prevent this and therefore effective management processes and policies are important, many small or old ships may not be sufficiently maintained to prevent this risk (ibid.). Such closed conditions could also be a contributory factor in a case of Legionnaires' exposure for a driver in a campervan that was used extensively during a 3-month trip (Euser et al. 2016).

\section{Food, Water, and Risk}

Another risk factor for tourism and tourists' health relates to the food they consume and the water they use and drink. For example, further incidences of legionella have been reported in static as well as mobile contexts. One such outbreak documented between 2016 and 2017 could not be isolated to a single accommodation source; however there was a reported increase in Legionnaires' disease cases associated with British, Swedish, and Dutch travelers returning from spending time in Dubai during that period (Dabrera et al. 2017) which suggests the source of the risk was destination rather than travel specific. Legionnaires' disease was also reported in a resort in Cozumel (Mexico) when the potable water system was identified as having affected nine travelers over a 2-year period from 2008 to 2010 (Hampton et al. 2016). Furthermore, hot water systems in Turkish baths have been cited as possible sources of Legionnaires' disease, based on evidence reviewed following a UK spa pool outbreak (Erdogan and Arslan 2015).

Other risk factors for tourists are the food preparation and hygiene standards of the destination. Travelers' diarrhea or "holiday sickness" can occur during or shortly after travel, and the primary causes are often cited as poor sanitation and poor food hygiene (Sheen et al. 2016). Some food purchases are viewed stereotypically as high risk, e.g., travelers' attitudes to street food vendors (Choi et al. 2013). This may be due to problems with lack of refrigeration, improper food storage or temperatures, and/or types of ingredients available to these microbusinesses which may well be operating with extremely limited resources. Other food options can also present problems. Even in the relative safety of a hotel, infections can rapidly spread (Henderson 2007). In 2007, an outbreak of gastrointestinal illness in a Dominican Republic resort affected at least 600 international travelers, and two flights returning to the UK on 9th of August had to be disinfected before returning to service (Health Protection Agency 2007). Gastrointestinal illnesses have similarly resulted in outbreaks of campylobacter, E. coli, listeria, and salmonella (World Health Organisation 2012). Another highly infectious gastrointestinal flu, norovirus, can be transmitted through contaminated food, water, or surfaces and from personto-person (Weinstein et al. 2008). It spreads in closed environments such as cruise ships, which can affect hundreds of passengers and lead to significant industry costs (Lun et al. 2017). Weinstein et al. (2008, p. 1203) go so far as to suggest that if an outbreak of norovirus occurs on a cruise ship, this could potentially provide an "early warning system" for winter norovirus outbreaks in the wider public as it may be an indicator of risk but this would require the systems in place to monitor such travel-specific outbreaks effectively.

The common association between the risk of food poisoning and travel destinations has led to a claims culture for the travel industry, and one such focus of these claims relates to gastric illnesses which have "soared" by an average of $520 \%$ between 2015 and 2016 (Gill 2017). This has the negative impact of creating a poor brand or destination image for the places and organizations reliant on tourism for economic prosperity. While there has been an abuse of the system (ibid.), the fact remains that tourists and travelers are at risk of illness from unsafe food and/or water. 
Another example of tourists becoming ill was traced to a swimming pool in a Mallorcan hotel when UK travelers suffered from cryptosporidiosis in 2003 (Launders et al. 2014). In 2009, a similar swimming pool outbreak of cryptosporidium affected UK travelers at a hotel complex in Turkey (Health Protection Agency 2009). Using data from 2014, Public Health England (2017) published a report on travel-associated cryptosporidium infection in England, Wales, and Northern Ireland. The report noted an $18 \%$ increase of cases in 2014 compared to 2013, with a threefold increase associated with Spain and twofold increase associated with Turkey. This may be related to the fact that Spain, France, and Turkey were the most reported countries of travel for cases of cryptosporidium (Public Health England 2017) as they are popular holiday destinations for UK tourists.

While hotels, cruise ships, airplanes, and other situations can create certain health risks, travelers to lesser developed countries (LDCs) face additional risks. Diseases, for instance, are more likely to exist in places that lack infrastructure such as running water, plumbing, water treatment, and other sanitation services. The World Health Organization (2012) report on International Travel and Health identifies several critical illnesses and diseases that may affect travelers to LDCs. Cholera, for instance, is spread by ingesting food or water inadvertently contaminated with feces or vomit and can in mild cases result in diarrhea and in serious and untreated cases be fatal (World Health Organization 2012). Tourists have also been known to contact typhoid which is spread by ingesting shellfish from sewage-polluted areas or contaminated milk products, with flies transferring the infection to foods (World Health Organization 2012). Another risk is that of giardiasis, a common parasitic infection transmitted through the indigestion of food or water that has fecal contamination, but as sexual contact can also lead to the spread, safe sex practices are recommended (Kelly and Shankaran 2016). While of course these health risks also affect local people around the world, tourists increase the number of people within a place and may put a strain on the limited resources of LDCs in terms of both the food and water available and also the health service provision.

\section{Vector-Borne Risks}

In contrast to (in)direct person-to-person disease transmission, vector-borne diseases are transmitted by arthropods such as mosquitos. Malaria is an important global challenge and serious hazard for 125 million travelers annually, particularly those lacking immunity (Jelinec 2015). As the World Health Organization (2012) explains, travelers to tropical and subtropical areas are at risk of being bitten by mosquitos during the transmission season. Symptoms range from headaches and vomiting to organ failure, coma, and, if untreated, death. These symptoms can appear up to 3 months after travel making diagnoses and containment challenging (World Health Organisation 2012). Therefore, although the mosquito bite could appear to be a relatively minor irritant to some tourists, the failure to seek pre-travel medical advice can have serious consequences during and post-travel. This is a particular issue for travelers who seek late availability holidays to reduce financial costs but who leave themselves without suitable knowledge or adequate time to start a course of preventative treatment.

A wide variety of adventure seekers including backpackers and nature and wildlife watchers could contract "monkey malaria" if they come into contact with a parasite that can affect travelers staying in rainforests and natural monkey inhabited areas such as Brunei, Singapore, Malaysia, the Philippines, Thailand, and Vietnam (World Health Organization 2012). Research by the London School of Hygiene and Tropical Medicine in Malaysian Borneo suggests that tree clearing is helping the macaques spread monkey malaria, due to their increased contact with humans (Thornton 2017). The significant increase in monkey malaria among local populations is now also being evidenced in tourists. Examples include tourists returning from Malaysia to Finland (Kantele et al. 2008), from Borneo to Sweden (Bronner et al. 2009), from Thailand to Germany (Kroidl et al. 2015), and from Thailand to France (Berry et al. 2011). Müller and Schlagenhauf (2014) further provide 
examples of tourists with monkey malaria returning to the USA, the Netherlands, Spain, France, Australia, and New Zealand. The increased interest by tourists in supporting wildlife conservation projects has spawned a range of products around the world, and by their very nature, such projects can draw tourists into areas that could make them more vulnerable to contracting monkey malaria. Furthermore, the practice of using food to entice animals from their natural habitats for the purpose of tourists viewing them may further exacerbate the problem due to increased proximity.

The risk to travelers' health depends on the local rate of disease transmission in the destination and their personal vaccination status (World Health Organization 2012). An example of a vector-borne disease, which can be mitigated by advance vaccination, is the yellow fever virus which is found in sub-Saharan Africa and tropical South America (World Health Organization 2012). This virus results in similar symptoms to malaria and is also transmitted by mosquito (ibid.). The importance of vaccination is illustrated by the example of nine unvaccinated European and US travelers who contracted the disease between 1970 and 2012, eight of which died as a result of their illness (ibid.). There are preventative medicines available for travelers to affected areas, although tourists are not always consistent with such medical advice (World Health Organization 2012). Tourists' commitment to the prescribed vaccination protocol is vital in managing the challenge; however as the WHO recognizes, tourists are not always a reliable part of the preventative strategies. Countries may insist on yellow fever vaccinations prior to entries to further protect not only their citizens but also their health services and their destination image or "brand" in terms of health security and associated risk perception.

Travelers are also at risk of being evacuated from their destination, for example, in serious cases of dengue fever (Wilder-Smith 2015). Tourists may experience increased risks due to factors such as seasonality, duration of trip, and the nature of the tourism activities they are undertaking (ibid.). Dengue fever is also transmitted by mosquito, and the same mosquito is also responsible for the transmission of chikungunya, a viral disease with symptoms including fever and severe joint pain. Travelers are at risk of infection when visiting areas that have such epidemics, and they can also spread the disease beyond the original outbreak area due to their increased level of mobility throughout and between different areas (World Health Organization 2018b). As a result, worldwide outbreaks of chikungunya have been linked to travel and migration due to occurrences in more temperate climates including France and Italy (ibid.). According to Myers (2014), an outbreak in December 2013 in St. Martin, Caribbean, spread so quickly that by the following year, it had been detected on 29 Caribbean islands (with 175,000 reported cases and 5000 confirmed cases); in 23 US states, Puerto Rico, and the US Virgin Islands (with 88 cases); and further afield. All Western Hemisphere cases were confirmed to involve tourists who had been to the Caribbean as part of their recent travel history (ibid.).

In addition to quite well-known travel health risks such as malaria and yellow fever that tourists are often advised about as part of their advance travel preparations, there are also less common diseases such as Japanese encephalitis which is also transmitted by mosquitos and can cause long-term neurologic and psychiatric conditions (Wilder-Smith 2015). Although it is considered a rare problem for travelers, the disease has spread to Australia and is increasingly found in Cambodia, Laos, and Myanmar (ibid.), and hence precautions are needed for tourists and tourism organizations.

To summarize, while there are numerous health risks associated with international travel and while it is not possible to provide an exhaustive list, it is important to recognize such risks in order to protect tourism stakeholders and local people within tourism destinations. The World Health Organization (2012) suggests that drug prevention levels need to be significantly improved in order for travelers to be aware of and hence able to minimize the associated risks. Tourism intermediaries can play a significant role in communicating any such risks and to inform would-be tourists about how to plan and prepare 
for their intended trips. However, the rise in online, direct holiday arrangements, e.g., booking flights or accommodation without using a tour operator or travel agency, may add to the challenge of building such awareness and may mean that travelers are poorly informed and lacking the necessary travel vaccinations and/or recommended medicines that may help them avoid becoming ill. This is not only important for the individual tourist but for the different people that may be at risk if the disease spreads both at destination level and on an international basis as a result. This highlights the importance of the public sector globally as there needs to be international coordination and cooperation that takes a universal perspective rather than individual tourists or private organizations being trusted or expected to take responsibility. All tourism stakeholders have a role to play when it comes to managing the risks and challenges related to travel and health.

\section{Tourism Behavior and Increased Risks}

There are also specific health risks relating to tourist behavior and the direct and indirect consequences of that behavior, and the following sections illustrate some of the critical issues relating to sexual risk taking and sexual exploitation in the context of tourism.

\section{Sexual Risk Taking}

Tourism is inherently hedonistic. It is seen as synonymous with the idea or desire for "sun, sea, sand and sex" and creates the opportunity for situational sexual disinhibition and experimentation (Berdychevsky and Gibson 2015). Escape from societal norms may account for tourists' increased propensity to engage in casual sex while on holiday (Matteelli et al. 2015). Being far from home and its associations with responsibility, reputation, parents, partners, and/or professional contexts can heighten a tourist's feelings of such an escape. This can potentially lead to a distortion of sexual risk perceptions within what can be openly permissive touristic environments (Berdychevsky 2017). A meta-analysis by
Svensson et al. (2018) recognizes several factors that may lead to increased sexual risk taking by tourists such as alcohol and drug intake, age, whether travelling alone or with friends, and duration of travel.

There are notable health consequences to such increased sexual risk-taking behavior of tourists, and these can have global significance. The World Health Organization (2012, p. 69) considers that a "large proportion of sexually transmitted infections now occur as a result of unprotected sexual intercourse during international travel." A lack of tourists' risk awareness can result in the contracting of STIs such as hepatitis B, syphilis, gonorrhea, chlamydia, and HIV/AIDS, which can result in chronic illness, infertility, disability, and death (ibid.). Sex education and sexual health resources are also significant factors in developing and/or poorer communities which may further increase the risks of infection not only for tourists but for local residents. There is also a lack of appreciation and/or commitment to preventative measures such as prophylactics (condoms specifically) by tourists which could reduce the risk of contracting an STI during travel (Matteelli et al. 2015).

\section{Sex Tourism}

In addition to the increased likelihood of tourists engaging in risky sexual behavior while abroad, there is also the recognition that sex is a primary motivation for some tourists. The World Tourism Organization (WTO 1995, p. 1) defined sex tourism as "trips organized from within the tourism sector, or from outside the sector but using its structure and networks, with the primary purpose of effecting a commercial sexual relationship by the tourist with residents at the destination." A resolution adopted by the 11th session of the General Assembly of the WTO, in Egypt, specifically focused on the prevention of organized sex tourism. The resolution recognized the "grave health as well as social and cultural consequences of such activity... especially when it exploits gender, age, social and economic inequality at the destination level" (ibid.). In making such a strong statement, the WTO called upon all tourism stakeholders both in originating (home) and 
visited (host) nations to take action. Sex tourism is therefore recognized as a global health issue and one that can place very vulnerable stakeholders at risk.

A further discussion around sex tourism concerns those who procure sex and those that facilitate sexual encounters, such as sex tours organized independently or through travel agents (Bang et al. 2014). In a study of websites selling sex tours, Gezinski et al. (2016) noted the emerging themes relating to enjoyment and acceptance, a "total girlfriend experience," and the exoticization of the "Third World" woman. However, this context provides a limited gender perspective, whereby male tourists seek to procure sex from women. To add to this discourse, De Albuquerque (1998) explored female sex tourists in the context of beach boys in the Caribbean and categorized the women as those who have sex with men as first-timers (neophytes), veterans (specific visit for sex, perhaps with multiple partners), and returnees (those returning to the same man for sex). An alternative dimension of sex tourism includes the "stag and hen" culture which has become a popular pre-marriage activity. This so-called rite of passage sees, for instance, a male "stag" engage in "excessive alcohol consumption and deviant, potentially harmful, behavior" (Briggs and Ellis 2017, p. 756). These samesex group travel opportunities provide the groom (or possibly the bride) their final hours of sexual freedom in destinations such as Amsterdam and Prague. Such sexual activity is not only undertaken with sex workers within the organized sex industry of some destinations but also with local residents and/or other tourists.

While some research has found there to be a desire for a relationship or emotional experience linked to sex tourism in its various guises, this is not to undermine the WTO's recognition that vulnerable stakeholders are increasingly likely to be exploited in a sex tourism setting due to the discernable gap between the rich tourist and the potentially poorer local resident. The inequality that the WTO highlights creates a space where power dynamics are difficult to ignore and the well-being of those involved is highly likely to be negatively affected by their experiences.
The lack of viable economic alternatives, lack of education and/or resources, and the sense of disempowerment that may result in being paid for sex may also affect other quality of life indicators and generally increase the physical and mental health risks for those involved. Strategies such as the WTO resolution and other industry codes of conduct need to focus on narrowing the window for exploitation within the context of sex tourism.

Carr (2016) recognizes that there is a scarcity of sex tourism research within tourism studies due to the fact that academics believe it lacks merit as an area of inquiry. Carr (2016) also suggests that there is a confused conceptualization of sex tourism potentially caused by different social constructs around sex tourists and sex providers and proposes the term "sex and tourism" rather than "sex tourism." Nevertheless, it is recognized that this still carries "social baggage" in relation to the word "sex" (ibid., p. 196), overall it is clear there is a fragmented picture, and this highlights scope for further research around this aspect of tourism.

\section{Child Exploitation and Tourism}

While there are many vulnerable groups within the context of sex tourism, children are exceptionally vulnerable and deserve recognition and protection from all industry stakeholders and indeed from all international perspectives. The aforementioned WTO resolution strongly "denounces and condemns in particular child sex tourism, considering it a violation of Article 34 of the [United Nation's 1989] Convention on the Rights of the Child."

Improved domestic tourism offerings and increased accessibility to international destinations across the globe provide the opportunity for some to take advantage of vulnerable children and engage in child sexual exploitation under the framework of travel and tourism (Hawke and Raphael 2016). This is an issue of global concern and affects the health and well-being of children directly affected by the sex tourism industry worldwide. There are various aggravating factors involved in this critical situation including those that are directly related to tourism, e.g., transport and travel providers, and also those that are 
indirectly related to tourism, e.g. granted permissions to cross borders using legal documentation, passports, visas, etc. Furthermore, differences in legal, ethical, and sociocultural frameworks mean that what is (un)available or (un)acceptable in one place may be very different in another and as a consequence may create complex supply and/or demand scenarios.

In the harsh realities of child sex tourism, the main purpose of travel for the "preferential offender" is to sexually exploit children, and these individuals seek ways to achieve this end (Hawke and Raphael 2016). One example of this may be the supposedly legitimate façade of engaging in voluntourism (whereby a tourist participates in voluntary work in an orphanage) which may bring the offender into a setting that necessarily includes vulnerable children (ibid.). Furthermore, the power imbalances are particularly evident in the corporate travel culture which can also be a façade masking the exploitation of children by international business tourists (ibid.). In addition to this, there are more cases where "situational offenders" unexpectedly find themselves in the position whereby they then choose to exploit a child or children (Hawke and Raphael 2016). The organization "End Child Prostitution, Child Pornography and the Trafficking of Children for Sexual Purposes" (ECPAT) supports an industry-led training initiative designed to protect children and prevent abuse. Some airlines and hotel chains have signed up as global members of the "Code of Conduct for the Protection of Children from Sexual Exploitation in Travel and Tourism" (Hawke and Raphael 2016), but there is a long way to go if the WTO's resolution is to be realized.

\section{Future Research}

From a global perspective, there is a need for awareness, shared responsibility, planning, and cooperation in order to ensure the health and well-being of all those involved directly and indirectly in tourism and travel.

In relation to tourism and the spread of disease and infection, future research could explore a number of gaps in the literature. For example, more could be understood about the risk perception and awareness of tourists in relation to travel-related health. Furthermore, research could explore the level of preparedness tourists can demonstrate at the outset of certain types of travel experiences. International ports of entry and departure could be useful research locations to develop an understanding of some of these issues. Tourism, management, health, and public sector research could usefully investigate the effective and various strategies used by countries and organizations in minimizing the risks in relation to travel and health, in order to draw out areas of best practice. This research could also develop theoretical contributions to knowledge.

Emerging industry challenges surrounding the travel sickness "claims culture" also warrant research in order to develop understandings of the merits, motivations, challenges, and consequences of such claims for the travel and tourism industry. Furthermore, research collaborations between health and tourism professionals would add value to theory and practice in both fields and foster quality while generating new understandings as a result.

In relation to tourism and sex, there is scope for further research in a number of areas including, but not limited to, gender and gendered experiences, age, and age-related groups including lesser represented groups such as the young and the older generations. Svensson et al. (2018) suggest that many studies relating to sex tourism to date focus on young men and identify the need for further research exploring differences in gender and age in this context. Tourism literature on sexual risk taking by women, for instance, has generally focused on sexually transmitted infections (STIs), and yet it is recognized to be more complex than this and hence warrants further research (Berdychevsky and Gibson 2015).

Finally, there is a need to consider communication channels. For example, in the context of the darker forms of sex tourism, there is scope to understand the role of technology and the internet throughout the supply chain and in potential preventative strategies. There is also a need to develop effective communication channels that 
reach intended audiences when seeking to inform and raise awareness more generally about health and tourism. This could include those needing travel-specific health information and support but also in terms of the WTO's resolution about education and awareness of the more critical issues around sex tourism.

\section{Cross-References}

Tourism \& Health: Understanding the
Relationship
Tourism and Health, Risks and Challenges

\section{References}

Bang B, Baker PL, Carpinteri A, Van Hasselt VB (2014) Sex tourism. In: Commercial sexual exploitation of children. Springer, Cham, pp 35-40

Berdychevsky L (2017) Sexual health education for young tourists. Tour Manag 62:189-195

Berdychevsky L, Gibson HJ (2015) Phenomenology of young women's sexual risk-taking in tourism. Tour Manag 46:299-310

Berry A, Iriart X, Wilhelm N et al (2011) Imported Plasmodium knowlesi malaria in a French tourist returning from Thailand. Am J Trop Med Hyg 84:535-538

Briggs D, Ellis A (2017) The last night of freedom: consumerism, deviance and the 'stag party'. Deviant Behav 38:756-767

Bronner U, Divis PC, Färnert A, Singh B (2009) Swedish traveller with Plasmodium knowlesi malaria after visiting Malaysian Borneo. Malar J 8:15

Carr N (2016) Sex in tourism: reflections and potential future research directions. Tour Recreat Res 41: 188-198

Choi J, Lee A, Ok C (2013) The effects of consumers' perceived risk and benefit on attitude and behavioral intention: a study of street food. J Travel Tour Mark 30:222-237

Dabrera G, Brandsema P, Lofdahl M et al (2017) Increase in Legionnaires' disease cases associated with travel to Dubai among travellers from the United Kingdom, Sweden and the Netherlands, October 2016 to end August 2017. Eur Secur 22:38

De Albuquerque K (1998) Sex, beach boys, and female tourists in the Caribbean. Sex Cult 2:87-112

Erdogan H, Arslan H (2015) Colonization of Legionella species in Turkish baths in hotels in Alanya, Turkey. Environ Monit Assess 187:235

Euser SM, Diederen BM, Bakker M et al (2016) Legionnaires' disease after a campervan holiday: a case report. J Travel Med 23:1. https://doi.org/10.1093/jtm/tav004
Gezinski LB, Karandikar S, Levitt A, Ghaffarian R (2016) 'Total girlfriend experience': examining marketplace mythologies on sex tourism websites. Cult Health Sex 18:785-798

Gill R (2017) Gastric illness claims soar 520\% in one year. In: Travel Trade Gazette. https://www.ttgmedia.com/ news/news/gastric-illness-claims-soar-520-in-oneyear-10341. Accessed 21 May 2018

Hampton LM, Garrison L, Kattan J et al (2016) Legionnaires' disease outbreak at a resort in Cozumel, Mexico. Open Forum Infect Dis 3:ofw170. Oxford University Press, Oxford

Hawke A, Raphael A (2016) Offenders on the move: global study on sexual exploitation of children in travel and tourism 2016. ECPAT International and Defence for Children - ECPAT, Bangkok

Health Protection Agency (2007) Outbreak of gastrointestinal illness in tourists visiting the Dominican Republic. In: The National Archives. http:// webarchive.nationalarchives.gov.uk/

20140714102004/http:/www.hpa.org.uk/hpr/archives/ 2007/news2007/news3307.htm\#dr. Accessed 31 Mar 2018

Health Protection Agency (2009) Gastroenteritis associated with travel to Turkey. In: The National Archives. http://webarchive.nationalarchives.gov.uk/ 20140714101830/http:/www.hpa.org.uk/hpr/archives/ 2009/news4209.htm\#turkey. Accessed 31 Mar 2018

Henderson JC (2007) Tourism crises: causes, consequences and management. Routledge, Oxford

Jelinec T (2015) Malaria. In: Zuckerman JN, Brunette G, Leggat $\mathrm{P}$ (eds) Essential travel medicine, 1st edn. Wiley, Chichester, pp 83-94

Kantele A, Marti H, Felger I et al (2008) Monkey malaria in a European traveler returning from Malaysia. Emerg Infect Dis 14:1434

Kelly U, Shankaran S (2016) Foodborne infectious disease in the international traveller. In: Food microbiology: in human health and disease. CRC Press, Boca Raton, pp 39-54

Kroidl I, Seilmaier M, Berens-Riha N et al (2015) Monkey malaria (Plasmodium knowlesi infection) after travelling to Thailand. Dtsch Med Wochenschr (1946) 140: 815-817

Laganà P, Gambuzza ME, Delia S (2017) Legionella risk assessment in cruise ships and ferries. Ann Agric Environ Med 24:276-282

LaRoque R, Ryan ET (2015) Respiratory disease. In: Zuckerman JN, Brunette G, Leggat P (eds) Essential travel medicine, 1st edn. Wiley, Chichester, pp 95-101

Launders NJ, Nichols GL, Cartwright R et al (2014) Selfreported stomach upset in travellers on cruise-based and land-based package holidays. PLoS One 9:e83425

Lun JH, Ressler K-A, Ferson MJ, White PA (2017) Norovirus and cruise ships. Microbiol Aust 38: 187-190

Matteelli A, Carvalho A, Cristina C, Schlagenhaul P (2015) Sexually transmitted infections. In: Zuckerman 
JN, Brunette G, Leggat P (eds) Essential travel medicine, 1st edn. Wiley, Chichester, pp 65-73

Müller M, Schlagenhauf P (2014) Plasmodium knowlesi in travellers, update 2014. Int J Infect Dis 22:55-64

Myers GN (2014) Tourism vector: mosquitos and travelers spread viral infection. In: Travel Weekly. http://www. travelweekly.com/Caribbean-Travel/Tourism-vector\% 2D\%2D-Mosquitos-and-travelers-spread-viral-infec tion. Accessed 19 May 2018

Public Health England (2017) Travel-associated cryptosporidium infection in England, Wales and Northern Ireland: 2014. Public Health England, London

Said MA, Perl TM, Sears CL (2008) Gastrointestinal flu: norovirus in health care and long-term care facilities. Clin Infect Dis 47:1202-1208

Sheen AJ, Zahid MSB, Fagbemi A et al (2016) 'Holiday sickness' - reported exploratory outcome of over 500 United Kingdom holidaymakers with travellers' diarrhoea. J Travel Med 24:1. https://doi.org/10.1093/ jtm/taw077

Svensson P, Sundbeck M, Persson KI et al (2018) A metaanalysis and systematic literature review of factors associated with sexual risk-taking during international travel. Travel Med Infect Dis (in press). https://doi.org/ 10.1016/j.tmaid.2018.03.002

Thombley ML, Stier DD (2010) Menu of suggested provisions for state tuberculosis prevention and control laws. US Department of Health and Human Services. Centers for Disease Control and Prevention, Atlanta
Thornton J (2017) Drones and phones: how mobile tech is fighting global diseases. In: London School of Hygiene and Tropical Medicine. https:/www.lshtm.ac.uk/ research/research-action/features/drones-and-phoneshow-mobile-tech-fighting-global-diseases. Accessed 19 May 2018

Weinstein RA, Said MA, Perl TM, Sears CL (2008) Gastrointestinal flu: norovirus in health care and longterm care facilities. Clin Infect Dis 47(9):1202-1208

Wilder-Smith A (2015) Vector-borne diseases. In: Zuckerman JN, Brunette G, Leggat P (eds) Essential travel medicine, 1st edn. Wiley, Chichester, pp 65-73

World Health Organization (2012) International tourism and health 2012. World Health Organisation, Geneva

World Health Organization (2018a) Communicable diseases. http://www.euro.who.int/en/health-topics/ communicable-diseases. Accessed 19 May 2018

World Health Organization (2018b) Dengue and severe dengue. In: World Health Organization. http://www. who.int/news-room/fact-sheets/detail/dengue-andsevere-dengue. Accessed 19 May 2018

World Tourism Organization (UNWTO) (2017) UNWTO tourism highlights: 2017 edition. World Tourism Organization (UNWTO), Madrid

World Tourism Organization (WTO) (1995) WTO statement on the prevention of organized sex tourism. 11th session, Res. A/RES/338 (XI) (Oct 17-22) 